\title{
Role of Dual Energy Computed Tomography in Evaluation of Renal Stones
}

\author{
MOHAMED SHAWKY, M.D.; TAHA M. TAHA, M.Sc. and TAREK F. ABD ELLA, M.D. \\ The Department of Radiodiagnosis, Faculty of Medicine, Menoufia University, Egypt
}

\begin{abstract}
Background: DECT is a new evolving technique used for in vivo prediction of renal stones chemical characterizations.

Aim of Study: This study aims to assess the role of Dual Energy computed Tomography (DECT) in evaluation of renal stone compositions.

Patients and Methods: This study is a prospective cohort study, it included 30 patients. Classic single energy examinations were done (100-120 kVp) followed by DECT performed by using a single-source dual energy with fast switching between two kilovoltages $(80,135 \mathrm{kVp})$. Results of DECT were then compared to crystallography.

Results: (20 males and 10 females) with known renal stones, no age or sex predilection. The patient aged from (16) to (79) years From all the examined 37 stones, DECT predicted chemical composition of stones as $24 \mathrm{Ca}$ oxalate stones, 8 uric acid stones and 5 cystine stones. DECT accurately identified all uric acid stones. DECT recognized 2 stones as $\mathrm{Ca}$ oxalate and they were proven to be Ca phosphate by crystallography. DECT also failed to identify mixed compositions in 2 stones which were diagnosed as $\mathrm{Ca}$ oxalate and cystine stones. Statistical analysis revealed reliable agreement between DECT and crystallography with a ( $p$-value) of $>0.001$ (highly significant).
\end{abstract}

Conclusion: DECT was found as an effective and reliable method in pre-analysis of renal stones prior to management.

Key Words: Dual Energy Computerized Tomography (DECT) - Renal stones.

\section{Introduction}

RENAL calculi affects about $10-14 \%$ of the population, with multiple different chemical compositions [1]

Unenhanced computed tomography has improved the ability to evaluate urinary calculi as it gives a good information about the presence, size

Correspondence to: Dr. Mohamed Shawky, The Department of Radiodiagnosis, Faculty of Medicine, Menoufia University, Egypt and location of the stones. DECT is a new evolving technique that provides similar information in addition to chemical characterizations of renal stones $[2,3]$.

From the physical aspect, three different concepts of DECT are available, the first concept is based on the technology of two X-ray tubes (known as dual source imaging) working simultaneously. The second method is based on the use of a duallayer multi-detector where the top layer of detectors absorbs most of the low-energy spectrum and the bottom detector layer absorbs higher energy photons. The third concept is based on the use of a single X-ray source with fast switching between two kilovoltage settings ( 80 and $140 \mathrm{kVp}$ ) at intervals of $0.5 \mathrm{~ms}$ during a single gantry rotation to generate high- and low-energy X-ray spectra $[4,5]$

Previous studies reported that DECT had a very high sensitivity and specificity for characterizing the chemical composition of renal stones [6].

Dual energy CT was reported recently to differentiate uric acid from non-uric acid [7].

A reliable prediction of the stone's chemical type helps the clinician to choose between treatment options, such as those composed of uric acid, may be treated medically and may not require surgery [8].

DECT : Dual Energy Computed Tomography.

$\mathrm{kVp}$ : Peak kilovoltage.

$\mathrm{Ca}$ : Calcium.

ESRD : End Stage Renal Disease.

HU : Hounsfield Unit.

ROI : Region of interest.

$\mathrm{kV}$ : Kilovoltage.

ESWL : Extracorporeal Shock Wave Lithotomy.

PCNL : Percutaneous Nephrolithotomy.

URS : Ureteroscopy. 
The most reported limitation of DECT is related to its relatively high irradiation, however multiple techniques are used to reduce radiation doses [9].

It is expected that DECT is going to replace the classic single energy $\mathrm{CT}$ as the main imaging modality in evaluating patients with suspected urinary calculi $[\mathbf{1 0 , 1 1 ]}$.

This study aimed to evaluate the role of DECT in renal stones characterization.

\section{Patients and Methods}

\section{Patients:}

This study, a prospective cohort study, was performed at the Radiology department at International Medical Centre "IMC", Cairo, throughout the period from August 2018 to March 2020. The study included 30 patients (20 males and 10 females) with known renal stones. The patient aged from (16) to (79) years with a mean age (47.5) years.

Informed written consents were obtained from all participants in the study after full explanation of the benefits and risks of the procedure. Privacy $\&$ confidentiality of all patient data are guaranteed. All data provision are monitored and used for scientific purpose only.

Inclusion criteria included patients previously diagnosed with renal stones larger than $3 \mathrm{~mm}$. No age or sex predilection. Exclusion criteria included contraindications to radiation e.g., pregnancy.

\section{Methods:}

I- Full history taking and clinical examination:

a- Personal history included age, sex and special habits as smoking, alcoholism.

b- History of the present illness.

c- Past history with special concern on known urolisthiasis.

d- Clinical examination including general examination, local abdominal and pelvic examination.

\section{II- Radiological examination:}

a- Ultrasonography:

Grey scale Ultrasonography (using LOGIQTM P9 Ultrasound System, GE Healthcare, USA.), for assessment of:

- Presence of renal stones or backpressure changes of the kidney.

\section{b- Computed Tomography:}

- CT machine: all patients were scanned with multidetector CT scanner, Aquilion ONE TM 640/ GENESIS Edition, Toshiba, Japan.
- Patient preparation:

- The patients are allowed to eat, drink and take their prescribed medications prior to the exam.

- The patients are advised to drink water 1-2 hours before the scan and maintain a full bladder.

- Image acquisition:

- The patient lying in supine position with head fixation and arms above the head then asked for holding breath at various times during the procedure.

- Technical scan parameters include: Field of view, patient's body size; scanogram, covering the area from the xiphisternum to the symphysis pubis; tube voltage, $100-120 \mathrm{kVp}$; tube current, $150 \mathrm{~mA}$ with automatic exposure control; slice thickness, $1 \mathrm{~mm}$; slice interval, 0 ; gantry rotation time, $0.5 \mathrm{sec}$. Axial images are then reconstructed in coronal and sagittal planes. For each patient, we evaluate the number, location, maximal diameter and CT density. CT density is measured with a region of interest "ROI" occupying less than $50 \%$ of the stone surface area.

- DECT examinations performed by using a singlesource dual energy with fast switching between two kilovoltages. Technical scan parameters for DECT scan include: Tube voltage, $80 \mathrm{kVp}$ and $135 \mathrm{kVp}$; reference tube current, $115 \mathrm{~mA}$ and $350 \mathrm{~mA}$ with automatic exposure control; field of view, patient's body size; slice thickness, $0.5 \mathrm{~mm}$; gantry rotation time, $0.5 \mathrm{sec}$.

- Post processing technique:

Images acquired with the dual energy modality were processed using the dedicated software of the CT machine for the evaluation of the stone chemical composition. After selection of both lowenergy and high-energy image volumes, stones are numbered in both low-energy and high-energy images. The end result is presented when the software then calculates the attenuation ratio of the stone and displays it as a point on the graph and colorize it by a red or blue color according to color map Fig. (1).

- Result display:

- Stone number, site, size and density in single energy (in HU).

- Attenuation value in single energy CT and DE (in HU).

- Attenuation ratio (low energy HU/high energy $\mathrm{HU}$ ) with colorization of the stone according to color map. 

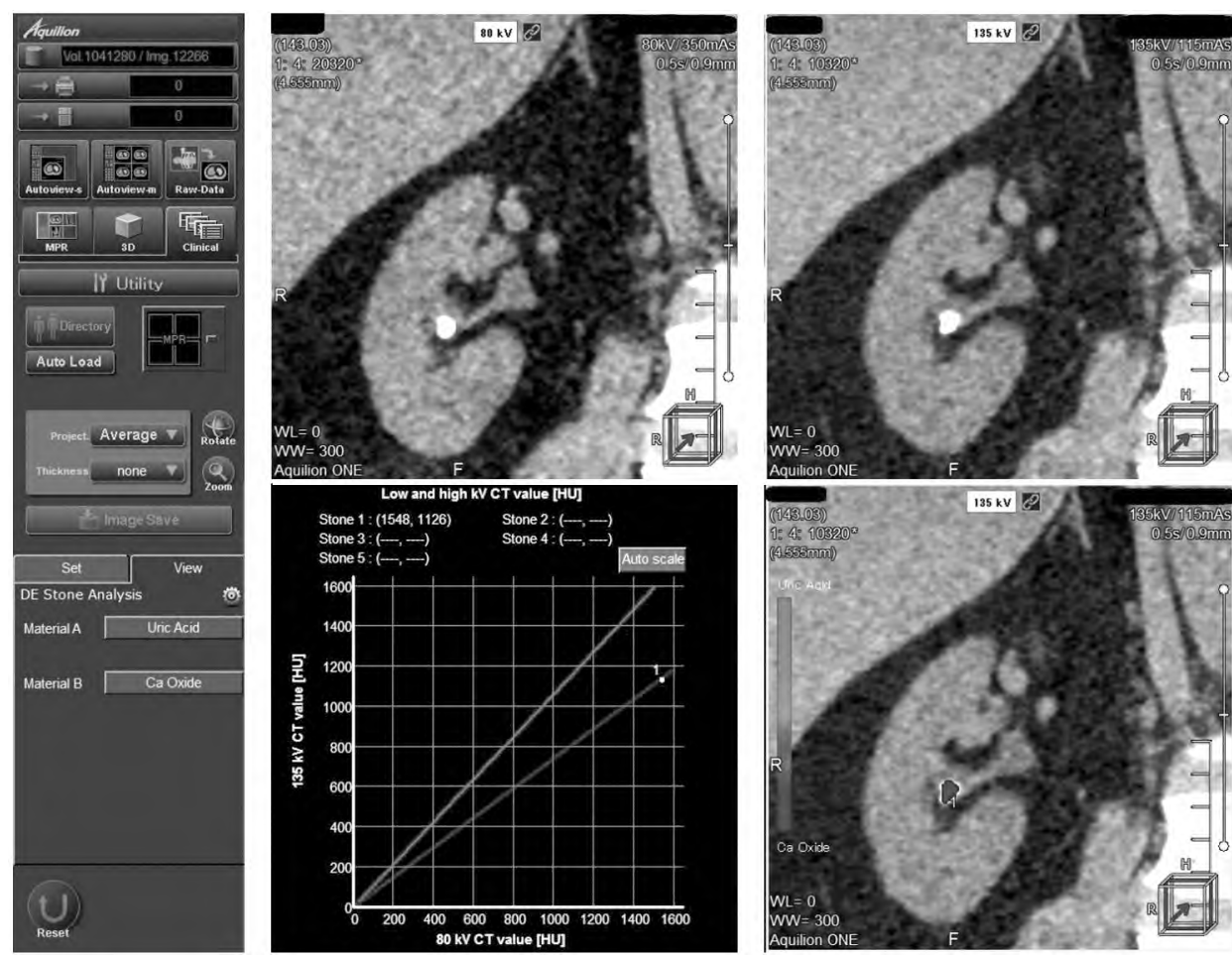

Fig. (1): The end result: The stone is represented by a point on the graph and colorized by red or blue color according to color map. This was a Ca oxalate stone.

\section{III- Laboratory stone analysis:}

All data were compared with result of laboratory stone analysis (crystallography) after passage or extraction of the stone.

\section{IV- Statistical analysis:}

Categorial and continuous variables were expressed and results were set in Tables and Figures using Microsoft Excel TM 2016. Agreement between DECT and laboratory stone analysis (crystallography) was estimated using Cohen's Kappa coefficient (k).

\section{Results}

This study included 30 patients, 20 males and 10 females. Their ages ranged from 16 to 79 years with a mean 48 years standard deviation (SD) of 14.2. Age and sex distribution is shown below (Table 1).

Clinical presentation of the patients was variable; classic loin pain was noted in 17 cases, hematuria in 5 cases, loin pain combined with hematuria in 3 patients, combined loin pain with nausea and vomiting in 3 patients, loin pain combined with fever in only 1 patient, one patient was asymptomatic. The percentage of each clinical presentation is shown in (Fig. 2).
Non-contrast computed tomography was performed for all patients. Twenty-five patients had a single stone and 5 patients had multiple stones, the total number of stones in the 30 examined patients was 37 stones. The sizes of stones ranged from 5 to $36 \mathrm{~mm}$ with a mean of $15 \mathrm{~mm}$. Single energy CT density ranged from $405 \mathrm{HU}$ to 1926 $\mathrm{HU}$ with a mean of $1124 \mathrm{HU}$. Eighteen stones were seen at the lower calyx, 4 stones seen at upper calyx, 3 stones seen at the middle calyx, 7 stones seen at the renal pelvis, 5 stones were staghorn stones. These findings are represented in (Fig. 3) and (Table 2).

DECT examinations performed by using a single-source dual energy with fast switching between two kilovoltage setting using $80 \mathrm{kVp}$ and $135 \mathrm{kVp}$. DECT predicted chemical composition of stones as $24 \mathrm{Ca}$ oxalate stones, 8 uric acid stones and 5 cystine stones. DECT accurately identified all uric acid stones Case example is shown in (Fig. 4). As DECT has only software criteria for Ca oxalate, Cystine and uric acid stones and the machine has no software criteria to detect other chemical compositions such as Ca phosphate, so in our study, DECT recognized 2 stones as Ca oxalate and they were proven to be $\mathrm{Ca}$ phosphate by crystallography. DECT also failed to identify mixed compositions in 2 stones which were diagnosed as Ca oxalate 
and cystine stones. These findings are represented in (Tables 3,4).

In our study, DECT recognized the chemical composition of uric acid stones ranging (405-530) HU for low-energy and (435-573) HU for highenergy with attenuation ratio of $(0.88-0.93)$. Cystine stones ranging (762-1200) HU for low-energy and (696-1002) HU for high-energy with attenuation ratio (1.09-1.21). Calcium oxalate stones ranging (1249-2151) HU for low-energy and (710-1561) HU for high-energy with attenuation ratio of (1.272.21). These values are detailed in (Table 5).

Patients underwent various treatment options according to stone site, size and chemical composition. In our study, 6 stones responded to medical treatment, 15 stones responded to Extracorporeal Shock Wave Lithotomy (ESWL), 13 stones under- went Percutaneous Nephrolithotomy (PCNL) and 3 stones needed open surgery. (Table 6).

Only one patient had a stone of $<5 \mathrm{~mm}$ in size, which was uric acid stone, so it responded to medical treatment. Twenty-one stones (6-<15mm); 4 of them were uric acid stones, 3 responded to medical treatment and one stone needed PCNL due to another larger stone in duplex calyceal system, 2 cystine stones responded to medical treatment and 15 stones were $\mathrm{Ca}$ oxalate of which 13 underwent ESWL and 2 needed PCNL after failure of ESWL. Six stones were (16-<20mm); 2 of them were uric acid failed medical treatment and needed PCNL, 4 were Ca oxalate, of them 3 responded to ESWL and one needed PCNL. Nine stones $>20 \mathrm{~mm} ; 6$ of them underwent PCNL and 3 needed open surgery regardless the chemical composition (Table 7).
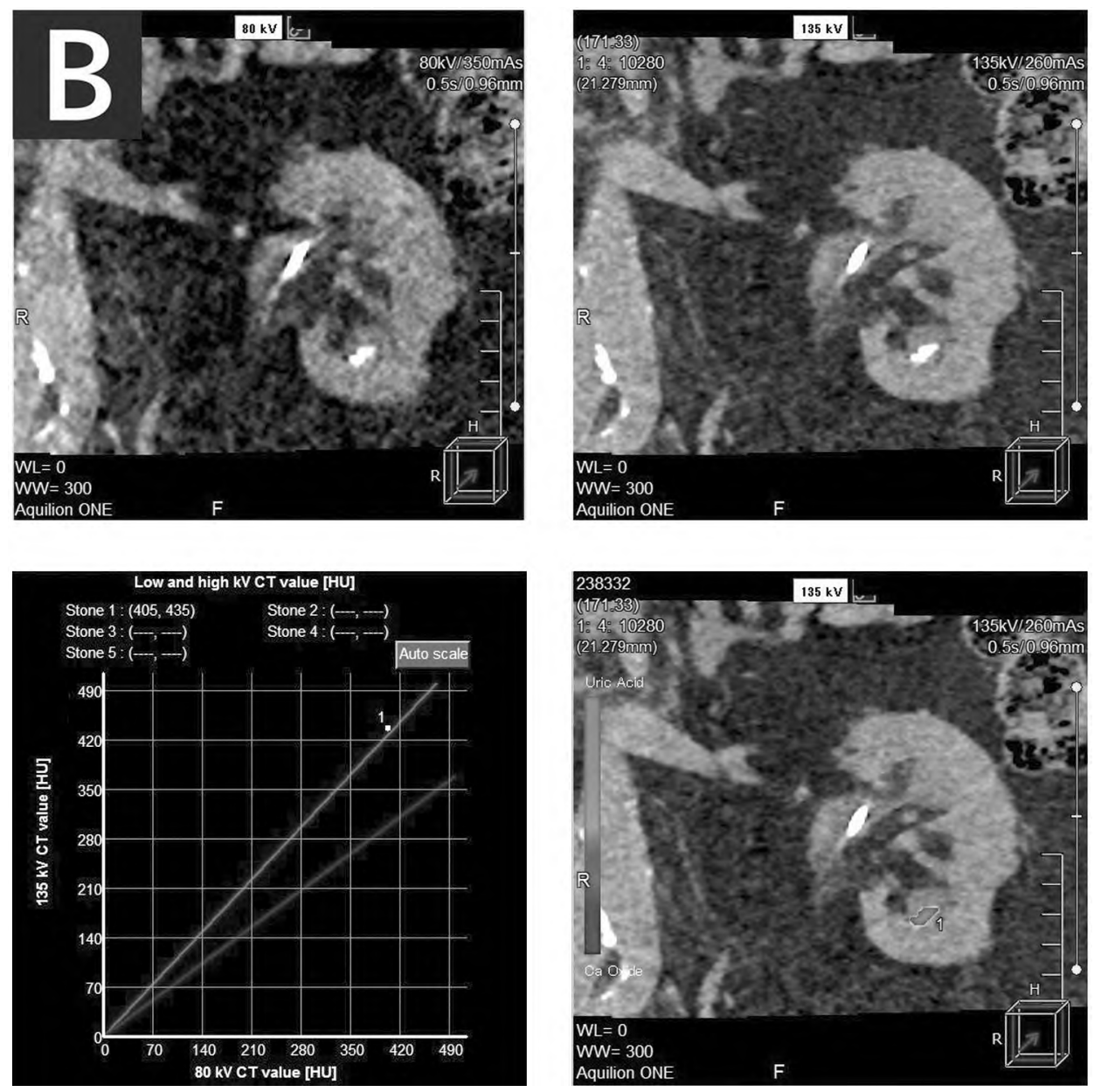

Fig. (2): Case (1): Dual energy chart showing attenuation of (405 and $435 \mathrm{HU}$ ) in low and high energy respectively, with attenuation ratio of (0.93), the stone is colorized by red color denoting uric acid composition according the color map. 
Clinical presentations of studied cases
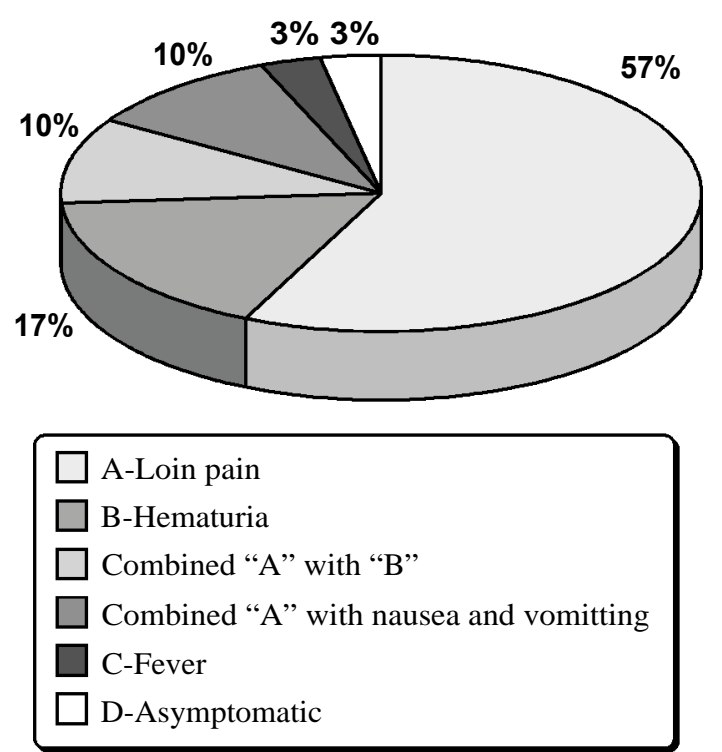

Fig. (3): Graph showing clinical presentations of the studied cases.

Table (1): Age and sex distribution of studied patients.

\begin{tabular}{|c|c|c|c|c|c|c|}
\hline \multirow{3}{*}{$\begin{array}{l}\text { Age in } \\
\text { years }\end{array}$} & \multicolumn{4}{|c|}{ Sex } & \multirow{2}{*}{\multicolumn{2}{|c|}{ Total }} \\
\hline & \multicolumn{2}{|c|}{ Male } & \multicolumn{2}{|c|}{ Female } & & \\
\hline & No. & $\%$ & No. & $\%$ & No. & $\%$ \\
\hline$<30$ & 1 & 3.3 & 1 & 3.3 & 2 & 6.6 \\
\hline $30<40$ & 6 & 20 & 1 & 3.3 & 7 & 23.3 \\
\hline $40<50$ & 5 & 16.6 & 2 & 6.6 & 7 & 23.3 \\
\hline $50<60$ & 4 & 13.3 & 3 & 10 & 7 & 23.3 \\
\hline $60<70$ & 3 & 10 & 2 & 6.6 & 5 & 16.6 \\
\hline$>70$ & 1 & 3.3 & 1 & 3.3 & 2 & 6.6 \\
\hline Total & 20 & 66.6 & 10 & 33.3 & 30 & 100 \\
\hline
\end{tabular}

Sizes of stones in examined patients (Total: 37 stones)

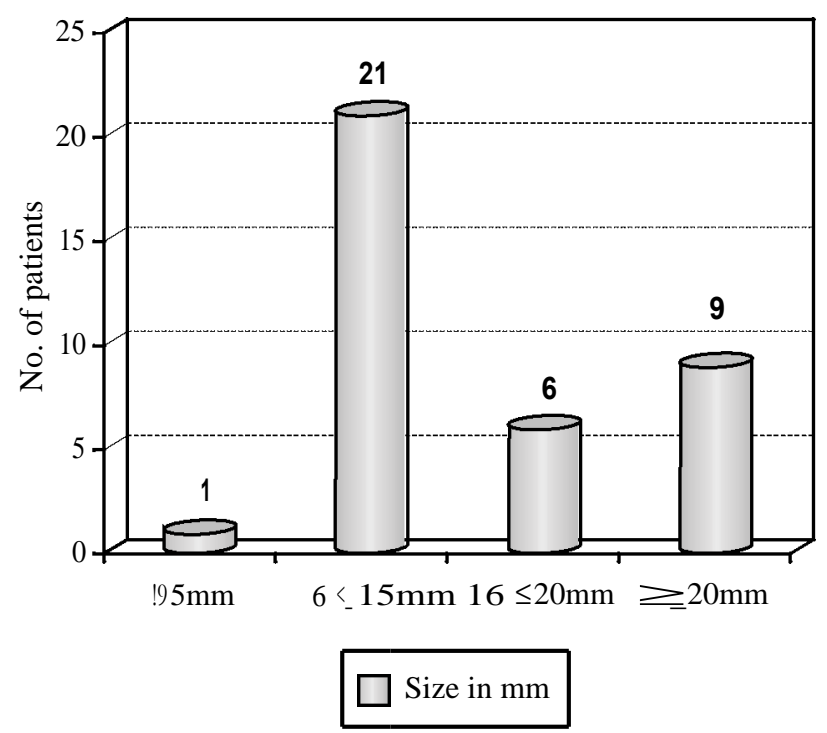

Fig. (4): Shows Sizes of stones in examined patients.

Table (2): Shows sites of stones in examined patients.

\begin{tabular}{lcccc}
\hline & Right & Left & Total & Percentage \\
\hline Upper calyx & 1 & 3 & 4 & 10.8 \\
Middle calyx & 2 & 1 & 3 & 8.2 \\
Lower calyx & 7 & 11 & 18 & 48.6 \\
Pelvis & 1 & 6 & 7 & 18.9 \\
Staghorn & 2 & 3 & 5 & 13.5 \\
\hline Total & 13 & 24 & 37 & 100 \\
\hline \multicolumn{5}{c}{ Nable (3): Different stone types predicted by DECT. } \\
\hline \multicolumn{5}{c}{ Number of stones } \\
\hline Ca Oxalate & 24 & Percentage \\
Uric acid & 5 & 64.8 \\
Cystine & 51.6 \\
\hline Total & 37 & 13.6 \\
\hline
\end{tabular}

Table (4): Agreement between DECT and crystallography.

\begin{tabular}{|c|c|c|c|c|c|c|}
\hline \multirow{2}{*}{ DECT } & \multicolumn{5}{|c|}{ Crystallography } & \multirow{2}{*}{$\begin{array}{c}\mathrm{X}^{2} \\
(p \text {-value })\end{array}$} \\
\hline & Calcium Oxalate & Calcium Phosphate & Cystine & Mixed & Uric Acid & \\
\hline $\begin{array}{l}\text { Calcium Oxalate } \\
(\mathrm{N}=24)\end{array}$ & $\begin{array}{l}21 \\
(100 \%)\end{array}$ & $\begin{array}{l}2 \\
(100 \%)\end{array}$ & 0 & $\begin{array}{l}1 \\
(50 \%)\end{array}$ & $\begin{array}{l}0 \\
0\end{array}$ & \multirow{4}{*}{$\begin{array}{c}69.529 \\
(>0.001 * *)\end{array}$} \\
\hline $\begin{array}{l}\text { Cystine } \\
(\mathrm{N}=5)\end{array}$ & 0 & 0 & $\begin{array}{l}4 \\
(100 \%)\end{array}$ & $\begin{array}{l}1 \\
(50 \%)\end{array}$ & 0 & \\
\hline $\begin{array}{l}\text { Uric Acid } \\
(\mathrm{N}=8)\end{array}$ & 0 & 0 & 0 & 0 & $\begin{array}{l}8 \\
(100 \%)\end{array}$ & \\
\hline $\begin{array}{l}\text { Kappa agreement } \\
\text { ( } p \text {-value) }\end{array}$ & & $\begin{array}{c}0.899 \\
(>0.001 * *)\end{array}$ & & & & \\
\hline
\end{tabular}

**: Highly significant. 
Table (5): Detailed data of DECT stone characterization.

\begin{tabular}{|c|c|c|c|c|c|}
\hline No. & Single energy HU & Low-energy HU & High-energy HU & Attenuation ratio & DECT stone type \\
\hline 1 & 505 & 475 & 535 & 0.88 & Uric Acid \\
\hline 2 & 413 & 410 & 457 & 0.89 & Uric Acid \\
\hline 3 & 405 & 467 & 520 & 0.89 & Uric Acid \\
\hline 4 & 439 & 425 & 468 & 0.90 & Uric Acid \\
\hline 5 & 461 & 439 & 475 & 0.92 & Uric Acid \\
\hline 6 & 536 & 530 & 573 & 0.92 & Uric Acid \\
\hline 7 & 489 & 458 & 492 & 0.93 & Uric Acid \\
\hline 8 & 408 & 405 & 435 & 0.93 & Uric Acid \\
\hline 9 & 704 & 762 & 696 & 1.09 & Cystine \\
\hline 10 & 962 & 964 & 864 & 1.11 & Cystine \\
\hline 11 & 853 & 927 & 780 & 1.18 & Cystine \\
\hline 12 & 1057 & 1200 & 1002 & 1.19 & Cystine \\
\hline 13 & 917 & 1035 & 849 & 1.21 & Cystine \\
\hline 14 & 1100 & 1249 & 978 & 1.27 & Calcium Oxalate \\
\hline 15 & 1286 & 1390 & 1081 & 1.28 & Calcium Oxalate \\
\hline 16 & 1183 & 1314 & 1019 & 1.28 & Calcium Oxalate \\
\hline 17 & 1456 & 1678 & 1298 & 1.29 & Calcium Oxalate \\
\hline 18 & 1442 & 1777 & 1366 & 1.30 & Calcium Oxalate \\
\hline 19 & 1577 & 1866 & 1432 & 1.30 & Calcium Oxalate \\
\hline 20 & 1495 & 1682 & 1272 & 1.32 & Calcium Oxalate \\
\hline 21 & 1799 & 1994 & 1500 & 1.32 & Calcium Oxalate \\
\hline 22 & 1202 & 1560 & 1173 & 1.32 & Calcium Oxalate \\
\hline 23 & 1169 & 1370 & 1027 & 1.33 & Calcium Oxalate \\
\hline 24 & 1554 & 1643 & 1228 & 1.33 & Calcium Oxalate \\
\hline 25 & 1178 & 1483 & 1104 & 1.34 & Calcium Oxalate \\
\hline 26 & 1407 & 1695 & 1257 & 1.34 & Calcium Oxalate \\
\hline 27 & 1620 & 1789 & 1312 & 1.36 & Calcium Oxalate \\
\hline 28 & 1585 & 1835 & 1344 & 1.36 & Calcium Oxalate \\
\hline 29 & 1634 & 1872 & 1361 & 1.37 & Calcium Oxalate \\
\hline 30 & 1926 & 2151 & 1561 & 1.37 & Calcium Oxalate \\
\hline 31 & 1306 & 1734 & 1256 & 1.38 & Calcium Oxalate \\
\hline 32 & 1384 & 1777 & 1282 & 1.38 & Calcium Oxalate \\
\hline 33 & 1249 & 1660 & 1180 & 1.40 & Calcium Oxalate \\
\hline 34 & 1116 & 1603 & 1069 & 1.49 & Calcium Oxalate \\
\hline 35 & 1466 & 1927 & 1231 & 1.56 & Calcium Oxalate \\
\hline 36 & 1241 & 1591 & 913 & 1.74 & Calcium Oxalate \\
\hline 37 & 1070 & 1571 & 710 & 2.21 & Calcium Oxalate \\
\hline
\end{tabular}

Table (6): Number of stones underwent various management options.
Table (7): Different management regarding size and chemical composition of stones.

\begin{tabular}{|c|c|c|c|c|c|c|}
\hline Management options & $\begin{array}{l}\text { Number } \\
\text { of stones }\end{array}$ & Percentage & Stone size & $\begin{array}{l}\text { Number } \\
\text { of stones }\end{array}$ & Composition & Management \\
\hline Medical treatment & 6 & 16.2 & $<5 \mathrm{~mm}$ & $\begin{array}{l}1 \\
3 \\
1\end{array}$ & $\begin{array}{l}\text { Uric acid } \\
\text { Uric acid } \\
\text { Uric acid }\end{array}$ & $\begin{array}{l}\text { Medical } \\
\text { Medical } \\
\text { PCNL }\end{array}$ \\
\hline $\begin{array}{l}\text { Extracorporeal Shock Wave } \\
\text { Lithotomy (ESWL) }\end{array}$ & 15 & 40.6 & $6 \leq 15 \mathrm{~mm}$ & $\begin{array}{l}2 \\
13\end{array}$ & $\begin{array}{l}\text { Cystine } \\
\text { Ca Oxalate }\end{array}$ & $\begin{array}{l}\text { Medical } \\
\text { ESWL }\end{array}$ \\
\hline Percutaneous Nephrolithotomy & 13 & 35.1 & & $\begin{array}{l}2 \\
2\end{array}$ & $\begin{array}{l}\text { Ca Oxalate } \\
\text { Uric acid }\end{array}$ & $\begin{array}{l}\text { PCNL } \\
\text { PCNL }\end{array}$ \\
\hline Open surgery & 3 & 8.1 & $16 く 20 \mathrm{~mm}$ & $\begin{array}{l}3 \\
1 \\
6\end{array}$ & $\begin{array}{l}\text { Ca Oxalate } \\
\text { Ca Oxalate } \\
\text { Various }\end{array}$ & $\begin{array}{l}\text { ESWL } \\
\text { PCNL } \\
\text { PCNL }\end{array}$ \\
\hline & & & $>20 \mathrm{~mm}$ & 3 & Various & Open Surgery \\
\hline Total & 37 & 100 & Total & & 37 & \\
\hline
\end{tabular}




\section{Discussion}

Characterization of urinary calculi using noninvasive methods can affect clinical management. CT has been the gold standard for diagnosis of urinary calculi, but has not reliably differentiated varying stone compositions. DECT has emerged as a technology to improve CT characterization of anatomic structures. The use of DECT allows us to address the composition of urinary stones, a key determinant in identifying suitable treatment $[12,13]$.

In our study, male to female ratio was $2: 1$, this ratio agreed with Knoll et al. (2011) [14], they found renal stones are more common in males with overall male to female ration of (2.4:1). This contrasts to other studies such as Dawoud et al. (2017) [15], they found renal stones were common in females $(55 \%)$ than males $(45 \%)$.

Our study included 30 patients, the ages of the patients ranged from 16 to 79 with a mean of 50 years and the peak age group was $40-50$ years ( 5 cases; $16.6 \%$ ). This agreed with Pearle et al. (2008) [16]; they studied two groups undergoing SWL and URS and the mean ages were (52.5 \pm 12.3$)$ and $(49.3 \pm 14.2)$ in the two groups respectively. These results differ from age groups determined by other studies such as Dawoud et al. (2017) [15], as they found the age group 30-40 were the most affected and the peak of 33 years.

One of the defects in our study is the small population, this may be referred to difficulties that we faced in the laboratory stone analysis because of its high coast and unavailability in our institute.

In our study, 19 patients (64\%) presented by loin pain, 7 patients (23\%) presented by hematuria, 3 patients (10\%) presented by nausea and vomiting, one patient $(3 \%)$ presented by combined loin pain and fever. These clinical presentations agree with most of the previous studies, one of the latest studies from Egypt, Dawoud et al. (2017) [15], found loin pain was the most common clinical presentation.

In our study, twenty-five patients had a single stone and 5 patients had multiple stones, the total number of stones in the 30 examined patients was 37 stones. The sizes of stones ranged from 5 to $36 \mathrm{~mm}$ with a mean of $15 \mathrm{~mm}$. Single energy CT density ranged from $405 \mathrm{HU}$ to $1926 \mathrm{HU}$ with a mean of $1124 \mathrm{HU}$. These findings agreed with Chaytor et al. (2016) [17], they found kidney stones are much more common $(84.7 \%)$ than ureteric stones, single stones were found in $79 \%$ of cases, however they found sizes of stones ranging from $3-48 \mathrm{~mm}$ with a mean of $8.8 \mathrm{~mm}$, this can be explain by the difference in number of examined patients; they examined 106 patients, compared to only 30 patients in our study.

In our study, DECT predicted chemical composition of stones as $24 \mathrm{Ca}$ oxalate stones, 8 uric acid stones and 5 cystine stones. DECT accurately identified all uric acid stones. These findings agreed with Dawoud et al. (2017) [15], Chaytor et al. (2016) [17] and Stolzmann et al. (2008) [18], they concluded that DECT was able to differentiate uric acid stones from non-uric acid stones using attenuation ratio analysis of DECT scanners.

In our study, DECT failed to identify $2 \mathrm{Ca}$ phosphate stones compared to crystallography, it also failed to identify mixed compositions in 2 stones which were diagnosed as $\mathrm{Ca}$ oxalate and cystine stones by crystallography. These findings agreed with Manglaviti et al. (2011) [6], they found DECT was unable to identify chemical compositions of 4 stones that were found to be mixed uric acid and $\mathrm{Ca}$ oxalate by crystallography while DECT characterized them as cystine and $\mathrm{Ca}$ oxalate.

In our study, only one patient had a stone of $<5 \mathrm{~mm}$ in size, which was uric acid stone, so it responded to medical treatment. Twenty-one stones $(6-\leq 15 \mathrm{~mm}) ; 4$ of them were uric acid stones, 3 responded to medical treatment and one stone needed PCNL due to another larger stone in duplex calyceal system, 2 cystine stones responded to medical treatment and 15 stones were $\mathrm{Ca}$ oxalate of which 13 underwent ESWL and 2 needed PCNL after failure of ESWL. 6 stones were $(16-\leq 20 \mathrm{~mm})$; 2 of them were uric acid failed medical treatment and needed PCNL, 4 were Ca oxalate, of them 3 responded to ESWL and one needed PCNL. Nine stones >20mm; 6 of them underwent PCNL and 3 needed open surgery regardless the chemical composition. These findings regarding the management of renal stones according to site, size and medical compositions agreed with multiple studies such as Habashy et al. (2016) [19], they concluded that distinguishing uric acid stones from calcium stones resulted in a change in patient management in the majority of their uric acid stone cases and avoided surgery in 12 patients ( $80 \%)$. Overall, 48 patients required a DECT scan for (identification and successful dissolution treatment of a uric acid stone. However, the impact of chemical composition preanalysis is still controversial. In studies such as Thomas et al, (2009) [18], calculus composition did not have an impact on the patient's clinical pathway, since in their institution, all calculi are 
extracted by the urology department by PNL or ureterorenoscopy whenever possible.

\section{Conclusion:}

DECT was found as an effective and reliable method in pre-analysis of renal stones prior to management. DECT is expected to replace the classic single energy CT as the main imaging modality to evaluate renal stones. DECT provides satisfactory information regarding the stone chemical composition, in addition to the basic information provided by single energy $\mathrm{CT}$, such as, number of stones, their sites, sizes, surfaces and CT densities. Identification of renal stone chemical composition affects the choice of treatment options and can reduce the usage of unnecessary invasive or semi-invasive options and improve the outcome of medical treatment.

We recommend further studies should be done to calculate attenuation ratio of multiple other stones such as Calcium Phosphate, so DECT could be used to identify such stones in the future.

\section{References}

1- CURHAN G.C.: Epidemiology of Stone Disease. Urol. Clin. North Am. Aug., 1; 34 (3): 287-93, 2007.

2- BOLL D.T., PATIL N.A., PAULSON E.K., et al.: Renal stone assessment with dual-energy multidetector CT and advanced postprocessing techniques: Improved characterization of renal stone composition-pilot study. Radiology. Mar., 1; 250 (3): 813-20, 2009.

3- GROSJEAN R., SAUER B., GUERRA R.M., et al.: Characterization of human renal stones with MDCT: Advantage of dual energy and limitations due to respiratory motion. Am. J. Roentgenol. Mar., 23; 190 (3): 720-8, 2008.

4- VLASSENBROEK A.: Dual Layer CT. In Springer, Berlin, Heidelberg, p. 21-34, 2011.

5- CHANDRA N. and LANGAN D.A.: Gemstone Detector: Dual Energy Imaging via Fast kVp Switching. In Springer, Berlin, Heidelberg, p. 35-41, 2011.

(6- MANGLAVITI G., TRESOLDI S., GUERRER C.S., et al. In vivo evaluation of the chemical composition of urinary stones using dual-energy CT. Am. J. Roentgenol. Jul., 23; 197 (1): W76-83, 2011.

7- PRIMAK A.N., FLETCHER J.G., VRTISKA T.J., et al.: Noninvasive Differentiation of Uric Acid versus NonUric Acid Kidney Stones Using Dual-Energy CT. Acad. Radiol. Dec., 1; 14 (12): 1441-7, 2007.
8- WILLIAMS J.C., SAW K.C., PATERSON R.F., et al.: Variability of renal stone fragility in shock wave lithotripsy. Urology. Jun., 1; 61 (6): 1092-6, 2003.

9- ASCENTI G., SIRAGUSA C., RACCHIUSA S., et al.: Stone-targeted dual-energy CT: A new diagnostic approach to urinary calculosis. Am. J. Roentgenol. Oct., 23; 195 (4): 953-8, 2010.

10- LI X.H., ZHAO R., LIU B., et al.: Determination of urinary stone composition using dual-energy spectral CT: Initial in vitro analysis. Clin. Radiol. Jul., 1; 68 (7): e3707, 2013.

11-AKAND M., KOPLAY M., ISLAMOGLU N., et al.: Role of dual-source dual-energy computed tomography versus $\mathrm{X}$-ray crystallography in prediction of the stone composition: A retrospective non-randomized pilot study. Int. Urol. Nephrol. Sep., 1; 48 (9): 1413-20, 2016.

12- FERRANDINO M.N., PIERRE S.A., SIMMONS W.N., et al.: First prize (Tie): Dual-energy computed tomography with advanced postimage acquisition data processing: Improved determination of urinary stone composition. J. Endourol. Mar., 24; 24 (3): 347-54, 2010.

13- SANAVI C., WERQUIN C., FEKIR A., et al.: Urinary stones: The contribution of dual energy $\mathrm{CT}$ and material decomposition. Diagn. Interv. Imaging, 94 (11): 1165-8, 2013.

14- KNOLL T., SCHUBERT A.B., FAHLENKAMP D., et al.: Urolithiasis through the ages: Data on more than 200,000 urinary stone analyses. J. Urol. Apr., 185 (4): 1304-11, 2011.

15- DAWOUD M.M., DEWAN K.A.A.W.A., ZAKI S.A., et al.: Role of dual energy computed tomography in management of different renal stones. Egypt J. Radiol. Nucl. Med. Sep., 1; 48 (3): 717-27, 2017.

16- PEARLE M.S., LINGEMAN J.E., LEVEILLEE R., et al.: Prospective Randomized Trial Comparing Shock Wave Lithotripsy and Ureteroscopy for Lower Pole Caliceal Calculi $1 \mathrm{~cm}$ or Less. J. Urol. May, 1; 179 (5 Suppl.): 2005-9, 2008.

17- CHAYTOR R.J., RAJBABU K., JONES P.A., et al.: Determining the composition of urinary tract calculi using stone-targeted dual-energy CT: Evaluation of a low-dose scanning protocol in a clinical environment. Br. J. Radiol. Nov., 21; 89 (1067): 20160408, 2016.

18- STOLZMANN P., SCHEFFEL H., RENTSCH K., et al.: Dual-energy computed tomography for the differentiation of uric acid stones: Ex vivo performance evaluation. Urol. Res. Aug., 11; 36 (3-4): 133-8, 2008.

19- HABASHY D., XIA R., RIDLEY W., et al.: Impact of dual energy characterization of urinary calculus on management. J. Med. Imaging Radiat. Oncol., 60 (5): 62431, 2016. 


\section{دور الأشعة المقطعية ثنائية الطاقة

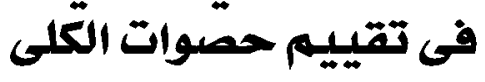

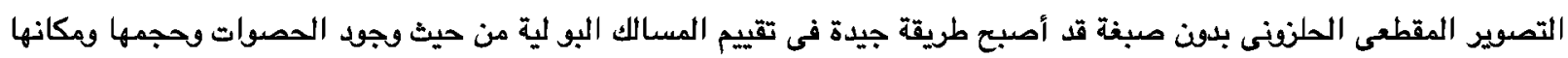

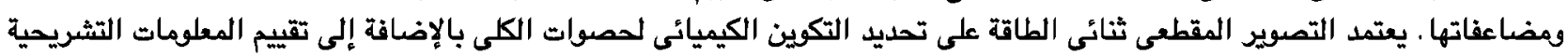

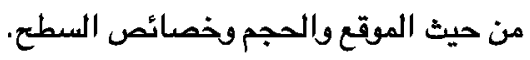

الأشعة المقطعية ثنائية الطاقة قد أثتبت كفاءة تقترب ... 1\% من فى تحديد المكونات الكيميائية لحصوات الكلى التى يزيد حجمها عن بملم.

$$
\text { تهذف هذه الدراسة إلى تقييم دود الأشعة المقطعية ثنائية الطاقة فى حصوات الكلى. }
$$

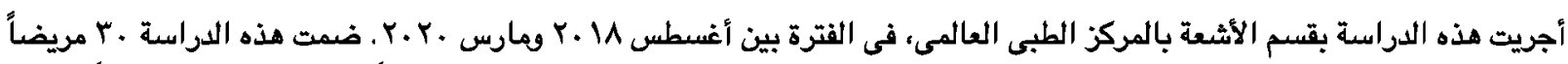

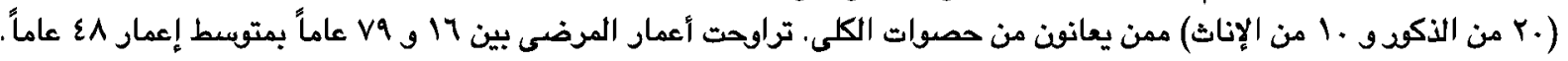

تم فحص المرضى بالأشعة المقطعية الأساسية أحادية الطاقة، بتيار أنبوب مقداره ـ Y كيلو فولت، ثم تم إجراء فحص الأشعة المقطعية

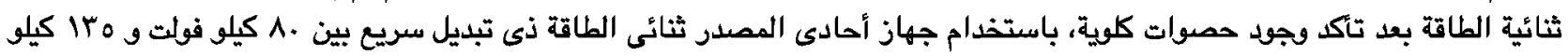
فولت، وبالتركيز على مكان الحصوات.

تمت معالجة الصود الناتجة باستخدام ورشة عمل الجهاز لتقييم المحتوى الكيميائى الحصوات.

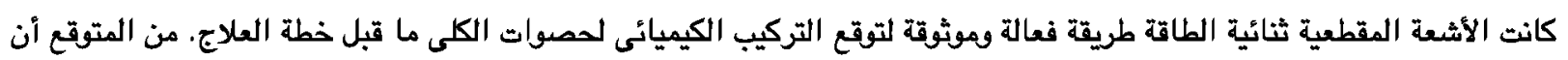

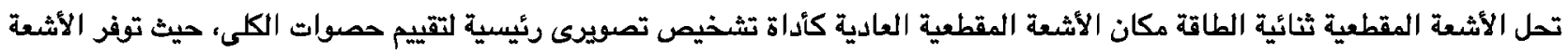

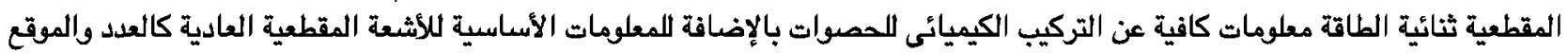

والحجم وشكل السطح والكثافة.

التعرف على التركيب الكيميائى لحصوات الكلى يؤثر في اختيار خطة العلاج، وقد يساعد في تقليل استخدام الإجراءات الاجتياحية غيرالضروية، ويحسن نتائج العلاج الدوائي. التيمياني 